\title{
СЕРЕДНІ РЕЗОНАНСНІ ПАРАМЕТРИ ЯДЕР ТЕЛУРУ I НЕОДИМУ
}

\author{
М.М. ПРАВДИВИЙ, І.О. КОРЖ, М.Т. СКЛЯР
}

Удк 539.171.4

(c) 2012

Інститут ядерних досліджень НАН України

(Просn. Науки, 47, Kиїв 03680; e-mail: sklyar@kinr. kiev.ua)

Із аналізу експериментальних диференціальних перерізів пружного розсіяння нейтронів у області енергії до 440 кеВ визначено повні набори середніх резонансних параметрів $S_{0}, S_{1}, R_{0}^{\prime}$, $R_{1}^{\prime}, S_{1,3 / 2}$ ядер телуру і неодиму з природним складом ізотопів. Проведено аналіз отриманих результатів, а також рекомендованих параметрів та деяких літературних даних.

\section{1. Вступ}

Дану роботу присвячено визначенню повних наборів середніх резонансних параметрів $S_{0}, S_{1}, R_{0}^{\prime}, R_{1}^{\prime}, S_{1,3 / 2}$ ядер телуру і неодиму з природним складом ізотопів за допомогою розробленого нами методу $[1,2]$. Визначення здійснено з аналізу середніх експериментальних диференціальних перерізів пружного розсіяння нейтронів із енергією до 440 кеВ. Метод виявився плідним як для отримання нових даних, так і для перевірки наявних у літературі параметрів на їх відповідність середнім експериментальним перерізам. Нейтронні силові функції ядер $S_{0}, S_{1}$ визначаються в основному з аналізу відомих параметрів розділених резонансів. На сьогодні для багатьох ядер виконано величезну кількість робіт, у котрих визначались силові функції. Однак труднощі визначення (мала кількість резонансів, неоднозначна ідентифікація їх за орбітальним моментом $l$ і т. п.) зумовили значні розкиди параметрів, визначених для одного і того самого ядра в різних лабораторіях. Внаслідок цього величини рекомендованих параметрів із появою нових даних часто змінюються у кілька разів [3-5]. Радіуси потенціального розсіяння $R_{0}^{\prime}, R_{1}^{\prime}$ визначаються іншими методами і практично незалежно від силових функцій. Фактично ці параметри визначаються розрізнено і тому часто не узгоджені між собою. У зв'язку з цим існує необхідність перевірки їх на відповідність експериментальним перерізам, усередненим по резонансах компаунд-ядра. Загалом середні перерізи з появою нових даних змінюються порівняно мало, і тому задовільний їх опис можна вважати вагомим критерієм надійності параметрів. Така перевірка сприятиме остаточному утвердженню залежностей резонансних параметрів від масового числа $A$, які нині грунтуються на розрахунках за оптичною моделлю. У даній роботі вона здійснена нами по відношенню до повних наборів резонансних параметрів, визначених у роботі [6] з аналізу в рамках $R$-матричної теорії середніх експериментальних перерізів пружного розсіяння нейтронів низьких енергій. Також було перевірено параметри $S_{0}, S_{1}, R_{0}^{\prime}$, рекомендовані Брукхевенською національною лабораторією (BNL) [4] та МАГАТЕ [5]. Між цими параметрами існують деякі розбіжності, що стало одним із стимулів для проведення наших досліджень.

Розроблений нами метод детально викладено у роботах $[1,2]$, тому нижче описано коротко лише його суть.

\section{2. Методика визначення середніх резонансних параметрів}

Розсіяння нейтронів ядрами при енергіях до $\sim 450$ кеВ здійснюється переважно 3 орбітальними моментами $l=0$ і $l=1$. У цьому випадку диференціальні перерізи пружного розсіяння можна розкласти за поліномами Лежандра у вигляді

$\sigma_{e l}(\mu)=\frac{\sigma_{e l}}{4 \pi}\left\{1+\omega_{1} P_{1}(\mu)+\omega_{2} P_{2}(\mu)\right\}$,

де $\mu=\cos \theta, \theta-$ кут розсіяння; $\sigma_{e l}-$ інтегральний переріз пружного розсіяння; $P_{l}-$ поліноми Лежан- 


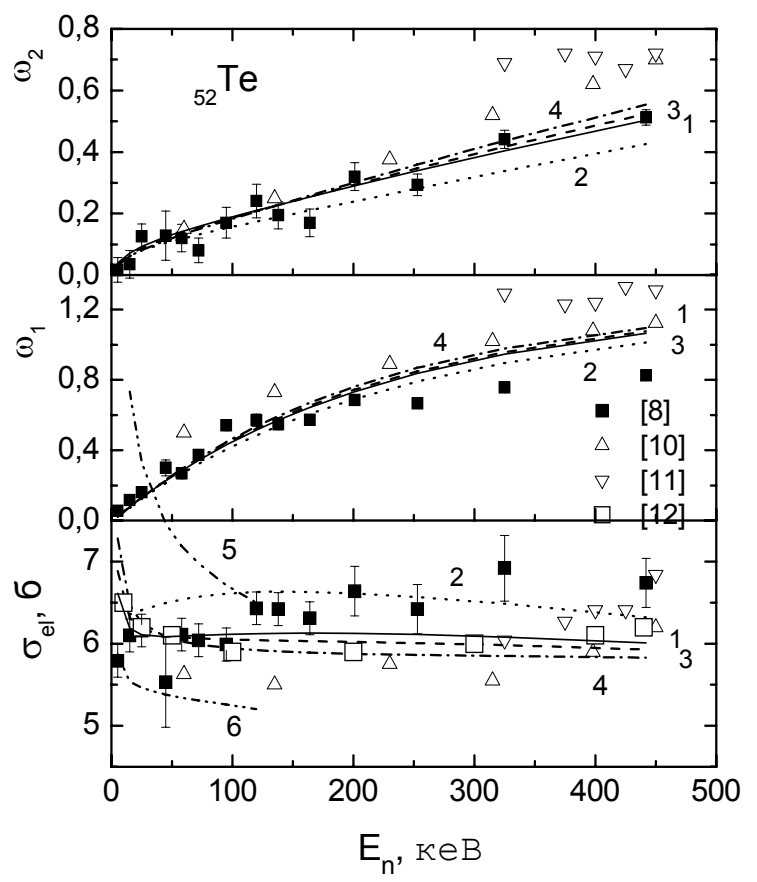

Рис. 1. Залежності від енергії величин $\sigma_{e l}, \omega_{1}, \omega_{2}$ ядер телуру. Символи - експериментальні дані. Криві - результати розрахунків (пояснення див. у тексті)

дра; $\omega_{1}$ і $\omega_{2}$ - коефіцієнти розкладання диференціальних перерізів. Ці коефіцієнти називаються кутовими моментами індикатриси розсіяння і дорівнюють $\omega_{l}=(2 l+1) \bar{P}_{l}$, де $\bar{P}_{l}-$ поліноми Лежандра, усереднені за кутами із вагою диференціального перерізу розсіяння. За умови $\sigma_{t} \approx \sigma_{e l}$ для парно-парних ядер нами було отримано вирази для коефіцієнтів розкладання:

$\omega_{1}=\frac{6 \pi \lambda^{2}}{\sigma_{e l}}\left(1-\eta_{0 R e}-\eta_{1 R e}+\eta_{0 R e} \cdot \eta_{1 R e}+\eta_{0 I m} \cdot \eta_{1 I m}\right)$,

$\omega_{2}=\frac{2}{\sigma_{e l}}\left(\sigma_{s 1}+\pi \lambda^{2} T_{1,3 / 2}\right)$

де $\eta_{l}=\eta_{l R e}+i \eta_{l I m}$ - діагональні елементи середньої матриці розсіяння; $\sigma_{s 1}$ - перерізи потенціального розсіяння нейтронів із $l=1 ; T_{1,3 / 2}-$ коефіцієнти проникності для $l=1$ i $j=3 / 2$.

В оптичній моделі перерізи $\sigma_{e l}$ складаються 3 відповідних парціальних перерізів компаундного і потенціального розсіяння нейтронів $\sigma_{e l}=\sigma_{c 0}+\sigma_{c 1}+\sigma_{s 0}+$ $\sigma_{s 1}$, які виражаються через матричні елементи $\eta_{l}$. У резонансній теорії середні перерізи також складаються із відповідних перерізів резонансного і потенціального розсіяння, які, у свою чергу, виражаються через середні резонансні параметри. У випадку вузьких резонансів $(\Gamma \ll D)$ парціальні перерізи оптичної моделі збігаються з відповідними перерізами резонансної теорії [7]. Це дозволяє матричні елементи $\eta_{l}$ виразити через резонансні параметри. Таким чином, якщо у рівняннях $(1)-(3)$ величини $\sigma_{e l}, \omega_{1}, \omega_{2}$ виразити через середні резонансні параметри, то підгонкою розрахованих величин $\sigma_{e l}, \omega_{1}, \omega_{2}$ до їх експериментальних значень можна визначити середні резонансні параметри $S_{0}, S_{1}, R_{0}^{\prime}, R_{1}^{\prime}, S_{1,3 / 2}$, які є параметрами підгонки. Із співвідношення $S_{1}=\left(S_{1,1 / 2}+2 S_{1,3 / 2}\right) / 3$ можна визначити параметр $S_{1,1 / 2}$. Для проведення розрахунків було використано відповідну програму підгонки по мінімуму $\chi^{2}$. Підгонку здійснювали одночасно по трьом величинам $\sigma_{e l}, \omega_{1}, \omega_{2}$, а контроль по $\chi^{2}$ можна було спостерігати для кожної величини окреMO.

\section{3. Отримані результати та їх аналіз}

Середні резонансні параметри $S_{0}, S_{1}, R_{0}^{\prime}, R_{1}^{\prime}, S_{1,3 / 2}$ ядер телуру і неодиму 3 природним складом ізотопів визначено нами з підгонки розрахованих величин $\sigma_{e l}, \omega_{1}, \omega_{2}$ до їх експериментальних значень, опублікованих, відповідно, у роботах [8] і [9] (на початку діапазону енергії нами проведено додаткове усереднення даних). Всі інші підгонки, описані нижче, було здійснено до даних цих робіт. Крім визначення нових даних, проведено перевірку повних наборів резонансних параметрів роботи [6] та розрізнених рекомендованих параметрів [4, 5] на їх відповідність експериментальним даним. Для ізотопів телуру і неодиму рекомендовано лише параметри $S_{0}, S_{1}[4,5]$ та $R_{0}^{\prime}[4]$, із яких розраховано середньозважені величини для природного складу ізотопів. При їх фіксації з автоматичної підгонки отримано решту параметрів із повного набору. Розраховані з цими наборами параметрів величини $\sigma_{e l}, \omega_{1}, \omega_{2}$ порівнювали із експериментальними. У всіх випадках якість опису експериментальних даних оцінювали за величиною $\chi^{2}$ та візуально на графіках.

\section{1. Телур}

На рис. 1 наведено енергетичні залежності експериментальних величин $\sigma_{e l}, \omega_{1}, \omega_{2}$ із роботи [8] та дані 3 робіт [10, 11]. Як видно, дані цих робіт проявляють значні розкиди та суттєві розбіжності між собою. Крім того, спостерігаються невизначеності у залежностях величин $\sigma_{e l}, \omega_{1}$ від енергії. Особливо значні розбіжності спостерігаються у перерізів $\sigma_{e l}$. Не внесли ясності і дані з повних перерізів, оскільки їх дуже мало і серед наявних також існують значні роз- 
киди [12]. На рисунку показано повні перерізи $\sigma_{t}$, усереднені у цій роботі. Кривими на рисунку показано результати розрахунків із різними наборами резонансних параметрів.

Кривими 2 наведено результати розрахунків із параметрами роботи [6]: $S_{0}=0,11(3) ; S_{1}=1,91(33)$; $R_{0}^{\prime}=6,57(14) ; R_{1}^{\prime}=8,04(42) ; S_{1,3 / 2}=1,72(28)$ (тут і далі силові функції виражені в одиницях $10^{-4}$, радіуси - в одиницях Фм; в дужках показано похибки). За наявних розкидів експериментальних даних та розбіжностей між даними різних авторів важко оцінити якість опису цим набором параметрів.

Кривими 3 наведено результати розрахунків із рекомендованими параметрами роботи [4]. Для ізотопів телуру рекомендовано параметри $S_{0}$ i $S_{1}$, із яких нами обчислено середньозважені величини: $S_{0}=0,29$; $S_{1}=1,43$. При їх фіксації з автоматичної підгонки отримано решту параметрів: $R_{0}^{\prime}=6,29 ; R_{1}^{\prime}=$ 8,$84 ; S_{1,3 / 2}=1,82$. 3 урахуванням існуючих розкидів експериментальних даних їх опис можна вважати задовільним і він є більш оптимальним для всієї сукупності даних, ніж першим набором. Необхідно додати, що у цій роботі для ізотопів телуру крім параметрів $S_{0}, S_{1}$ рекомендовано також параметри $R_{0}^{\prime}$, із яких обчислено середньозважену величину $R_{0}^{\prime}=5,47$. Ця величина зовсім не узгоджується із залежністю від масового числа $A$. Набір параметрів, визначений з підгонки при фіксації рекомендованих величин: $S_{0}, S_{1}$ і $R_{0}^{\prime}=5,47$, зовсім не описує перерізи - розраховані перерізи значно менші навіть за дані, наведені у роботі [10].

У роботі [5] для ізотопів телуру рекомендовано параметри $S_{0}$ i $S_{1}$, із яких нами обчислено середньозважені величини: $S_{0}=0,37 ; S_{1}=1,19$. При їх фіксації з автоматичної підгонки отримано решту параметрів: $R_{0}^{\prime}=6,28 ; R_{1}^{\prime}=9,15 ; S_{1,3 / 2}=1,70$. Результати розрахунків на рисунку наведено кривими 4. Величини параметрів цього набору близькі до попереднього, i тому результати розрахунків також близькі.

Як видно із рис. 1 , експериментальні величини $\sigma_{e l}$, $\omega_{1}, \omega_{2}$ роботи [8] проявляють значні розкиди та невизначеності в їх залежностях від енергії. У таких умовах визначати резонансні параметри 3 автоматичної підгонки немає сенсу, оскільки величини $\chi^{2}$ не можуть служити надійним критерієм якості опису експериментальних даних. Тому новий набір параметрів нами визначено шляхом підбору їх величин: $S_{0}=0,25 ; S_{1}=1,70 ; R_{0}^{\prime}=6,22 ; R_{1}^{\prime}=8,65$; $S_{1,3 / 2}=1,91$. Результати розрахунків на рисунку наведено кривими 1. Як видно, опис експериментальних даних є більш оптимальним, ніж в інших наборах, а

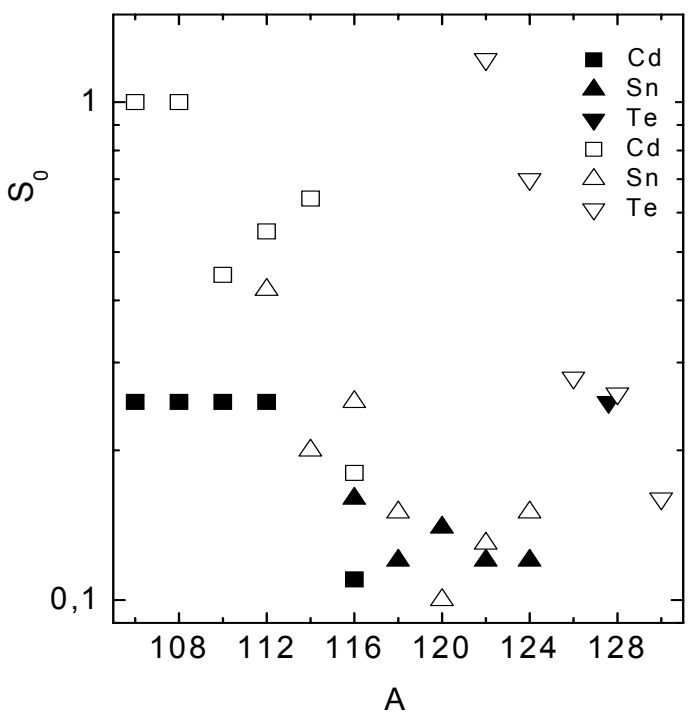

Рис. 2. Параметри $S_{0}$ ядер кадмію, олова і телуру

величини $\chi^{2}$ загалом менші. Отримані нами параметри в межах похибок узгоджуються з рекомендованими [4] і тим самим підтверджують їх надійність. Але цей висновок відноситься лише до середньозважених величин для телуру з природним складом ізотопів, оскільки рекомендовані для окремих ізотопів величини параметрів $S_{0}$ і $S_{1}$ відрізняються у $2-5$ разів.

У зв'язку з цим необхідно згадати проблему, яка існує уже давно і до цього часу ще остаточно не вирішена [3-5]. Найбільші розкиди величин параметрів $S_{0}$ спостерігаються у мінімумі їх залежності від $A$ в області $A \sim 90-130$. Внаслідок їх невизначеності стримується вдосконалення розрахунків за оптичною моделлю. Загалом у ізотопів більшості елементів ці розкиди мають хаотичний характер. Але в ізотопів кадмію, олова і телуру величини параметра $S_{0}$ проявляють систематичне і різке зменшення з ростом $A$, що протирічить розрахункам по оптичній моделі, згідно 3 якими вони повинні зростати $[3,4]$.

На рис. 2 наведено силові функції $S_{0}$, отримані для парних ізотопів кадмію та олова раніше у наших дослідженнях [2] і для телуру в даній роботі (чорні символи) та рекомендовані у роботах $[4,5]$. Як видно, рекомендовані величини різко зменшуються з $A$. Очевидно, що відповідним чином це повинно проявлятись і в середніх експериментальних перерізах. Але аналіз експериментальних даних із $\sigma_{e l}, \omega_{1}, \omega_{2}$ ізотопів кадмію [13] показав, що в залежностях від енергії вони проявляють хаотичні розкиди і на їх фоні помітних систематичних змін даних від $A$ не спостерігається. 


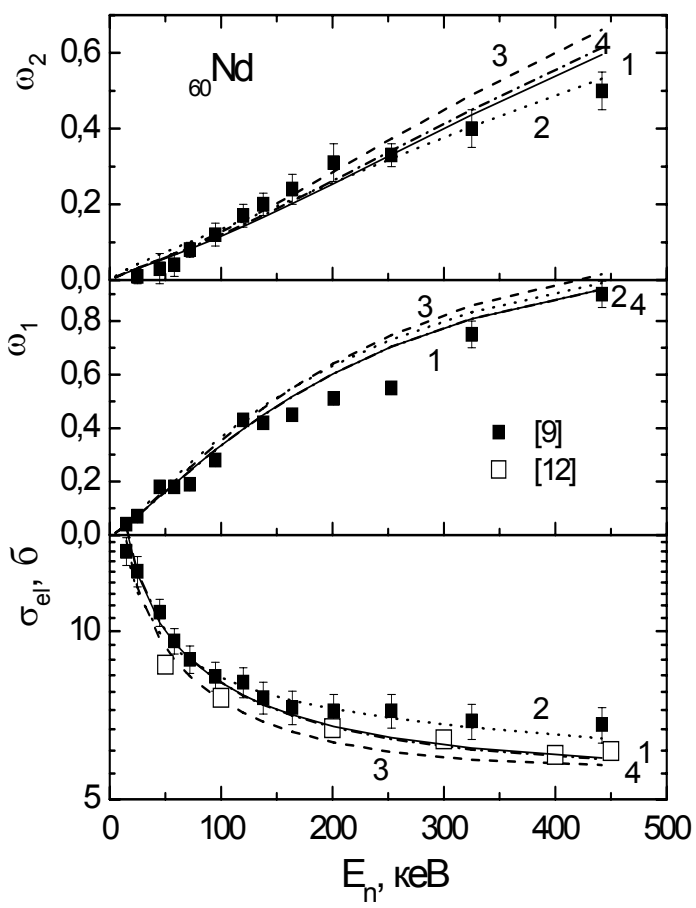

Рис. 3. Те ж саме, що і на рис. 1, для телуру

Аналогічний висновок було зроблено і щодо перерізів ізотопів олова [8]. Це підтверджено також аналізом повних перерізів ізотопів олова, виміряних у роботі [14] в області енергї 20-1400 кеВ. У них спостерігається плавне незначне зменшення перерізів із зростанням $A$. У цій роботі резонансні параметри визначено двома способами: зі статистичного аналізу виміряних авторами експериментальних даних (повні перерізи, перерізи радіаційного захвату, пропускання) та з розрахунків за оптичною моделлю. Отримані нами величини параметра $S_{0}$ (рис. 2) узгоджуються 3 даними цієї роботи. Для наявних експериментальних перерізів вони є оптимальними, і їх збільшення до рекомендованих значень неодмінно приводить до значного погіршення опису перерізів на початку діапазону енергї. Крім того, рекомендовано лише параметри $S_{0}$ і $S_{1}[4,5]$, інші параметри необхідно було визначати з автоматичної підгонки до експериментальних даних. У результаті внаслідок великого значення параметра $S_{0}=1,0$ для ізотопа ${ }^{108} \mathrm{Cd}$ отримано величину параметра $R_{0}^{\prime}=4,4$, яка зовсім не узгоджується із залежністю від $A$ (в області $A \sim 100-110-$ $\left.R_{0}^{\prime} \sim 6,5\right)$ [4]. Аналогічну ситуацію спостерігали і в інших ізотопів кадмію та олова з великими значеннями параметра $S_{0}$.

Для ізотопів телуру експериментальних даних $\sigma_{e l}$, $\omega_{1}, \omega_{2}$ у літературі не існує і тому немає можливо- сті оцінити надійність рекомендованих для них величин параметра $S_{0}$ використаним нами способом. Але можна якісно показати вплив величин параметрів на розраховані перерізи. На рис. 1 наведено перерізи $\sigma_{e l}$, розраховані нами 3 використанням рекомендованих для ізотопів телуру параметрів [5]: ${ }^{122} \mathrm{Te}-S_{0}=1,22$; $S_{1}=1,7 ;{ }^{1,30} \mathrm{Te}-S_{0}=0,16 ; S_{1}=0,82$. Для обох ізотопів було взято одну і ту саму величину радіуса потенціального розсіяння ' $R_{0}=6,19$, яка загалом $є$ середньою для всіх ізотопів і добре узгоджується 3 рекомендованою залежністю цього параметра від $A$ [4]. Результати розрахунків перерізів з використанням параметрів $S_{0}, S_{1}$ і $R_{0}^{\prime}$ на рисунку наведено, відповідно, кривими 5 і 6 . Як видно, між ними існує значна різниця і відповідна різниця повинна бути і між величинами експериментальних перерізів цих ізотопів. Хоча таких даних не існує, але немає підстав чекати у них якихось ізотопних ефектів, відмінних від тих, що спостерігаються в ізотопів кадмію й олова.

Таким чином, із проведених нами досліджень випливає, що згадана аномалія в залежності величин параметра $S_{0}$ від $A$ у ізотопах кадмію і олова не відповідає середнім перерізам. Однак великі різниці між величинами параметра $S_{0}$, які отримано з підгонки до середніх експериментальних перерізів, і рекомендованими [3-5], що отримано з аналізу відомих параметрів розділених резонансів, вимагають відповідного пояснення, оскільки важко уявити, що вони $€$ результатом експериментальних похибок. Тому для остаточного вирішення цієї проблеми необхідно провести ще додаткові експериментальні та теоретичні дослідження.

\section{2. Неодим}

На рис. 3 наведено енергетичні залежності експериментальних величин $\sigma_{e l}, \omega_{1}, \omega_{2}$ із роботи [9]. Оскільки інші дані відсутні, то для перевірки надійності перерізів $\sigma_{e l}$ цієї роботи на рисунку зображено усереднені повні перерізи $\sigma_{t}$ із роботи [12]. Як видно, перерізи $\sigma_{e l}$ систематично більші за перерізи $\sigma_{t}$. Можливою причиною цього були залишки водню у зразку, про що пишуть автори роботи [9]. Крім того, у цій роботі при енергіях 325 кеВ і 442 кеВ наведено лише дані з перерізів $\sigma_{e l}$, а дані з $\omega_{1}, \omega_{2}$ відсутні. Із рисунка видно, що їх відсутність при наявних розкидах знижує надійність визначених резонансних параметрів під час здійснення автоматичних підгонок, оскільки вони в певній мірі визначають хід їх залежностей від енергіi. Тому у розрахунках використано величини $\omega_{1}, \omega_{2}$, отримані шляхом певного усереднення. На рисунку 


\begin{tabular}{c|c|c|c|c|c|c}
\multicolumn{2}{l}{ Середні резонансні параметри ядер телуру і неодиму } \\
\hline$Я_{\text {дро }}$ & $S_{0} \cdot 10^{4}$ & $S_{1} \cdot 10^{4}$ & $R_{0}^{\prime}, \Phi_{\mathrm{M}}$ & $R_{1}^{\prime}, \Phi_{\mathrm{M}}$ & $S_{1,1 / 2} \cdot 10^{4}$ & $S_{1,3 / 2} \cdot 10^{4}$ \\
\hline $\mathrm{Te}$ & $0,25(10)$ & $1,70(30)$ & $6,22(25)$ & $8,65(45)$ & $1,28(1,20)$ & $1,91(40)$ \\
$\mathrm{Nd}$ & $3,30(20)$ & $0,90(20)$ & $6,75(22)$ & $9,62(65)$ & $0,40(85)$ & $1,15(30)$ \\
\hline
\end{tabular}

вони наведені як дані роботи [9]. Проведені розрахунки довели доцільність цієї процедури, хоча незначні зміни їх величин суттєво не впливають на величини визначених параметрів, а лише на величини $\chi^{2}$.

Кривими 2 на рисунку наведено результати розрахунків величин $\sigma_{e l}, \omega_{1}, \omega_{2}$ із параметрами роботи [6]: $S_{0}=2,80(20) ; S_{1}=2,10(60) ; R_{0}^{\prime}=6,31(50)$; $R_{1}^{\prime}=9,64(1,1) ; S_{1,3 / 2}=1,51(27)$. Із експериментальних величин $\sigma_{e l}, \omega_{1}, \omega_{2}$ задовільно описані лише перерізи $\sigma_{e l}$, що досягнуто за рахунок збільшення величини параметра $S_{1}$, яка не узгоджується із залежністю його від $A$ [4]. У інших даних помітні розбіжності, зумовлені скоріше їх розкидами.

Із рекомендованих для ізотопів неодиму [4] резонансних параметрів нами отримано середньозважені параметри для природного складу ізотопів: $S_{0}=$ 3,$30 ; S_{1}=0,81 ; R_{0}^{\prime}=6,27$. Із автоматичної підгонки отримано решту параметрів: $R_{1}^{\prime}=10,18 ; S_{1,3 / 2}=$ 1,10 . Результати розрахунків $\sigma_{e l}, \omega_{1}, \omega_{2}$ на рисунку наведено кривими 3. Як бачимо, розраховані перерізи систематично менші від експериментальних $\sigma_{e l}$ i $\sigma_{t}$, а також розрахованих за допомогою першого набору параметрів.

$\mathrm{У}$ роботі [5] для ізотопів неодиму рекомендовано величини параметрів $S_{0}$ i $S_{1}$, із яких нами отримано середньозважені величини: $S_{0}=3,36 ; S_{1}=0,81$. При їх фіксації з автоматичної підгонки визначено решту параметрів: $R_{0}^{\prime}=6,74 ; R_{1}^{\prime}=9,71 ; S_{1,3 / 2}=1,20$. Результати розрахунків на рисунку наведено кривими 4. Як видно, задовільно описані повні перерізи, а опис коефіцієнтів $\omega_{1}, \omega_{2}$ приблизно такий самий, як і у кривих 3.

Із рисунка видно, що всі три набори параметрів приблизно однаково описують коефіцієнти $\omega_{1}, \omega_{2}-$ і візуально, і за величиною $\chi^{2}$. Помітно більші розбіжності спостерігаються у розрахованих перерізах. Внаслідок невизначеності величин експериментальних перерізів важко судити про якість їх опису. Шляхом підбору величин параметрів нами проведено розрахунки з метою отримати оптимальний опис експериментальних даних. У результаті було отримано такий набір параметрів: $S_{0}=3,30 ; S_{1}=0,90$; $R_{0}^{\prime}=6,75 ; R_{1}^{\prime}=9,62 ; S_{1,3 / 2}=1,15$. Результати розрахунків на рисунку наведено кривими 1. Видно, що розраховані перерізи помітно менші від даних роботи [9] і краще узгоджуються з повними перерізами [12], а величини $\omega_{1}, \omega_{2}$ описані не гірше за попередні набори і візуально, і за величиною $\chi^{2}$. Отримані величини параметрів $S_{0}, S_{1}, R_{0}^{\prime}$ у межах похибок узгоджуються 3 рекомендованими параметрами і цим підтверджують їх надійність.

Отже, проведені розрахунки свідчать про те, що ті параметри, які задовільно описують середні перерізи, загалом узгоджуються з їх залежностями від $A$, в основі яких лежать розрахунки за оптичною моделлю. Якщо в досліджених наборах параметрів є параметри, величини яких мають помітні відхилення від цих залежностей, то це неодмінно погіршує опис експериментальних перерізів.

Отримані в даній роботі резонансні параметри наведено в таблиці.

\section{4. Висновки}

У даній роботі визначено нові повні набори середніх резонансних параметрів $S_{0}, S_{1}, R_{0}^{\prime}, R_{1}^{\prime}, S_{1,3 / 2}$ для ядер телуру і неодиму з природним складом ізотопів. Отримані для обох ядер параметри загалом задовільно описують наявні експериментальні дані і при цьому узгоджуються із залежністю від масового числа $A$ [4], розрахованою за оптичною моделлю. Загалом підтверджено рекомендовані для обох ядер величини параметрів $S_{0}, S_{1}$. Також підтверджена величина параметра $R_{0}^{\prime}$, рекомендована для ядер неодиму [4]. Для телуру рекомендована величина параметра $R_{0}^{\prime}=5,47$ не підтверджена, оскільки вона не узгоджується з залежністю від $A$, а набір параметрів, отриманий із підгонки за участю цієї величини, незадовільно описує експериментальні перерізи.

1. M.M. Pravdivy, I.O. Korzh, and M.T. Sklyar, Ukr. J. Phys. 49, 627 (2004).

2. І.О. Корж, М.М. Правдивий М.Т. Скляр, Середні резонансні параметри парних ізотопів кадмію $i$ олова Proc. of the Intern. Conf. Curr. Probl. in Nucl. Phys. and At. Energy (NPAE, Kyiv, 2006), May 29 - June 03, Kyiv, Ukraine (Kyiv 2007), Part II, P. 599.

3. S.F. Mughabghab, M. Divadeenam, and N. E. Holden, Neutron Cross Section. BNL-325 (Academic Press, New York, 1981), Vol. 1, Pt. A. 
4. S.F. Mughabghab, Atlas of Neutron Resonances (Resonance Parameters and Thermal Cross Sections), 5-th edition (Elsevier, Amsterdam, 2006), Vol. 1.

5. R. Capote, M. Herman, P. Oblozinsky, P.G. Young, S. Goriely, T. Belgya, A.V. Ignatyuk, A.J. Koning, S. Hilaire, V.A. Plujko, M. Avrigeanu, O. Bersillon, M.B. Chadwick, T. Fukahori, Zhigang Ge, Yinlu Han, S. Kailas, J. Kopecky, V.M. Maslov, G. Reffo, M. Sin, E.Sh. Soukhovitskii, and P. Talou, Nucl. Data Sheets 110, 3107 (2009) [http//www.nds.iaea.org/RIPL-3/].

6. А.Б. Попов, Г.С. Самосват, Спин-орбитальные эффекты в резонансном и потенииальном рассеянии $p$ волновых нейтронов (Краткие сообщ. ОИЯИ, № 18 86 Дубна, 1986); Г.С. Самосват Анизотропия упругого рассеяния нейтронов и свойства ядер ЭЧАЯ 17, вып. 4. 713 (1986).

7. А.А. Лукьянов Структура нейтронных сечений 191 (Атомиздат, Москва, 1978).

8. Зо Ин Ок, В.Г. Николенко, А.Б. Попов, Г.С. Самосват, (Сообщения ОИЯИ № P3 85 133, Дубна, 1985).

9. А.Б. Попов, Г.С. Самосват, Дифференциальные сечения упругого рассеяния килоэлектронвольтных нейтронов на ядрах (Сообщения ОИЯИ, № P3 86599. Дубна, 1986).

10. A. Langsdorf, R.O. Lane, and J.E. Monahan, Phys. Rev. 107, 1077 (1957).

11. A.B. Smith and R. Hayes, Nucl. Phys. A 93, 609 (1967).

12. V. McLane, C. Dunford, and P.F. Rose, Neutron Cross Section. BNL-1988 (Academic Press. New York, 1988), Vol. 2.
13. A.B. Popov and G.S. Samosvat, Preprint JINR E3-85226 (Dubna, 1985).

14. В.М. Тимохов, Боховко М.В., Исаков А.Г. и др., Ядерная физика 3(9) 50, 609 (1989).

Одержано 11.07.11

\section{СРЕДНИЕ РЕЗОНАНСНЫЕ ПАРАМЕТРЫ ЯДЕР \\ ТЕЛЛУРА И НЕОДИМА}

Н.М. Правдивыци, И.А. Корж, Н.Т. Скляр

$\mathrm{P}$ е $з$ ю м е

Из анализа экспериментальных дифференциальных сечений упругого рассеяния нейтронов в области энергии до 440 кэВ определены полные наборы средних резонансных параметров $S_{0}, S_{1}, R_{0}^{\prime}, R_{1}^{\prime}, S_{1,3 / 2}$ ядер теллура и неодима с естественным составом изотопов. Проведен анализ полученных результатов, а также рекомендованных параметров и некоторых литературных данных.

\section{AVERAGE RESONANCE PARAMETERS OF TELLURIUM AND NEODYMIUM NUCLEI}

M.M. Pravdivy, I.O. Korzh, M.T. Sklyar

Institute for Nuclear Research, Nat. Acad. of Sci. of Ukraine (47, Prosp. Nauky, Kyiv 03680, Ukraine;

e-mail: sklyar@kinr.kiev.ua)

$\mathrm{S} \mathrm{u} \mathrm{m} \mathrm{m} \mathrm{a} \mathrm{r} \mathrm{y}$

Complete sets of average resonance parameters $S_{0}, S_{1}, R_{0}^{\prime}, R_{1}^{\prime}$, and $S_{1,3 / 2}$ for tellurium and neodymium nuclei with natural isotope contents have been determined by analyzing the experimental differential cross-sections of neutron elastic scattering in the energy range lower than $440 \mathrm{keV}$. The data obtained, the recommended parameter values, and some literature data have been analyzed. 